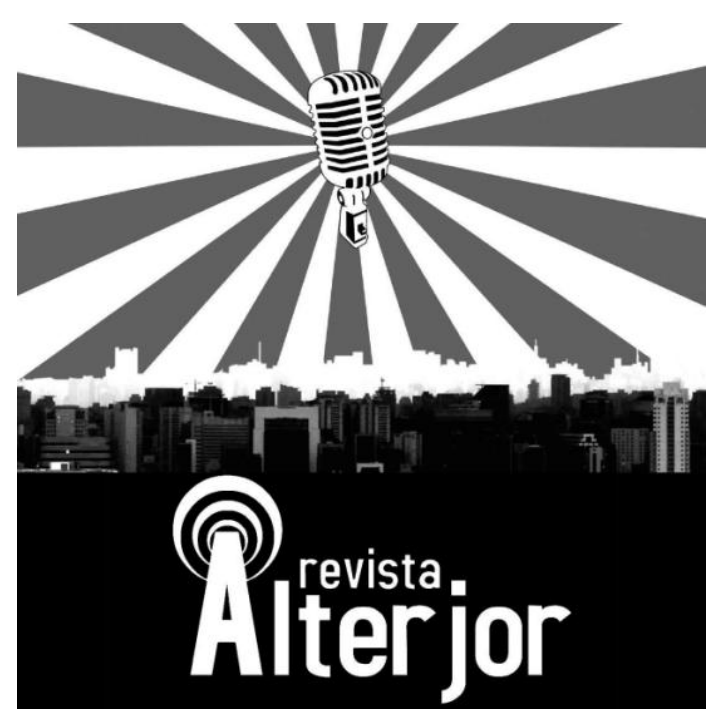

\title{
POSSIBILIDADES DE ATUAÇÃO PARA AS ORGANIZAÇÕES NO UNIVERSO CIENTÍFICO BRASILEIRO: ESTUDO DE CASO DO GRUPO CLAUDINO
}

\author{
Keynayanna Késsia Costa Fortaleza ${ }^{1}$
}

\begin{abstract}
RESUMO: A sociedade brasileira passa por um momento extremamente delicado no que diz respeito ao reconhecimento, a importância social e a validação de projetos ligados ao universo científico. Divulgar a ciência e seus resultados positivos para a vida em sociedade tornou-se um grande desafio para a classe científica do país. Diante desta realidade, este artigo se caracteriza como bibliográfico (STUMPF, 2005) e documental (MOREIRA, 2005) e tem como objetivo explorar como as organizações, enquanto agentes sociais diretos nas comunidades onde atuam podem investir e beneficiar a ciência no Brasil. O estudo de caso se dará junto a um conglomerado sediado no Piaú, o Grupo Claudino, que desde a década de 1970 investe em projetos de ordem educativos, sociais e científicos. Para fundamentar teoricamente essa reflexão, foi realizada uma revisão bibliográfica embasada nos seguintes autores dos campos da Comunicação, Educação e Jornalismo Científico: Burkett (1990) , Bacegga (2009), Citelli (2009), Lima (2017), Kaplún (1998), dentre outros pesquisadores do tema.
\end{abstract}

PALAVRAS-CHAVE: Comunicação. Organizações. Ciência. Grupo Claudino. Brasil.

ABSTRACT: Brazilian society is going through an extremely delicate moment in terms of recognition, social importance and validation of projects linked to the scientific universe. Disseminating science and its positive results for life in society has become a major challenge for the country's scientific class. Given this reality, this article is characterized as bibliographic (STUMPF, 2005) and documentary (MOREIRA, 2005) and aims to explore how organizations, as direct social agents in the communities where they operate, can invest and benefit science in Brazil. The case study will take place with a conglomerate based in Piauí, the Claudino Group, which since the 1970s has invested in educational, social and scientific projects. To theoretically base this reflection, a bibliographic review based on the following authors from the fields of Communication, Education and Scientific Journalism was carried out: Burkett (1990), Bacegga (2009), Citelli (2009), Lima (2017), Kaplún (1998), among other researchers on the topic.

KEYWORDS: Communication. Organizations. Science. Claudino Group. Brazil.

${ }^{1}$ Doutoranda em Comunicação na ECA/USP. Bolsista CAPES. Mestra em Comunicação pela PUCRS.
Jornalista, Pedagoga e Gestora em Educomunicação. E-mail: keynayanna@usp.br.

Revista ALTERJOR

Grupo de Estudos Alterjor:Jornalismo Popular e Alternativo (ECA-USP)

Ano 10 Volume 02 Edição 22 Juho-Dezembro de 2020

Avenida Professor Lúcio Martins Rodriģues, 443, Cidade Universitária, São Paulo, CEP: 05508-020 


\section{INTRODUÇÃO}

Devido aos eventuais processos de ordens políticos, sociais, culturais e econômicos que a sociedade brasileira esta passando na contemporaneidade fica cada vez mais visível as necessidades e as carências de informações que a população possui no âmbito da ciência e tecnologia. Para compreender esta situação, precisamos primeiro nos situarmos como está a realidade educativa do nosso país, pois a educação é a base para todo e qualquer projeto a ser desenvolvido no âmbito da ciência, além de proporcionar intelectualmente as pessoas o mínimo de entendimento sobre a ciência que está sendo feita no Brasil.

Infelizmente, as mazelas educativas em nossa realidade brasileira são de ordem histórica. Os projetos que envolvem o desenvolvimento das políticas educativas em nosso país são burlados desde a época em que o Brasil era uma colônia de exploração. São muitos anos de desresponsabilização com a educação, que envolve uma cultura da exclusão que privilegia apenas o capitalismo desenfreado. Se voltarmos ao passado e analisarmos as nossas origens formativas iremos observar que a educação no Brasil sempre foi elitizada, envolvendo muita desigualdade social, atos de corrupção e parcos recursos, com as bases legais de um financiamento marcado por períodos de "avanços e recuos, já que se insere dentro de contextos sócios- históricos diferenciados que fazem delas um processo e um produto socialmente construído" (CURY, 2018, p. 1218).

Olhando para passos futuros, o Brasil seguiu com alto grau de analfabetismo, estes somam mais de 13 milhões, seres sociais desprovidos de capacidade crítica e intelectual. Tal realidade incide diretamente na ciência, pois sem uma base educativa a sociedade brasileira não compreende o que é de fato a "ciência", a sua importância para beneficiar as comunidades, como o governo deve arcar com suas responsabilidades formativas e como as organizações $^{2}$ podem e devem atuar junto à ciência no país, proporcionando novas possibilidades junto à promoção de educação e cidadania.

\footnotetext{
${ }^{2}$ Neste estudo, ao nos referirmos a organização, também utilizamos os termos conglomerado empresarial e corporação, entendendo-os como sinônimos.
} 


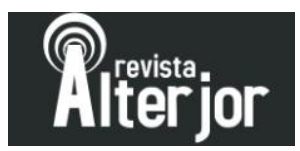

Acreditamos que esse contexto histórico no âmbito educativo e social incidiu negativamente nos investimentos e no próprio reconhecimento das potencialidades exercidas pela ciência no país. Hoje, enquanto brasileiros, o que vivenciamos publicamente com os cortes realizados em muitos projetos científicos em desenvolvimento, principalmente nas universidades federais do país, são a prova viva, de que nem o governo federal está ciente do poder e do impacto da ciência em nossas vidas. É preciso mobilização e muita atenção, tanto da classe que atua no âmbito das pesquisas, como da própria sociedade, que busca pelo conhecimento crítico e por melhores condições de vida.

Para Burkett (1990) a ciência estuda o mundo, ela é a chave para o conhecimento público, sendo uma atividade humana que tem como principal objetivo melhorar a sociedade. Chaimovich (2000) ressalta que a importância da valorização da ciência para o desenvolvimento brasileiro é hoje evidente. Mesmo diante de tantas dificuldades, o Brasil possui seus méritos e conquistas no âmbito científico. Apesar de a sociedade brasileira ter baixa taxa de escolaridade, no âmbito da ciência o país se mantém como referência no desenvolvimento de pesquisas e publicações acadêmicas, principalmente na América Latina. Silva (2017) destaca que:

A ciência brasileira teve um crescimento, entre os anos de 2000 e 2009 , de $205 \%$, chegando a $2,69 \%$ do total da produção científica mundial, segundo dados do National Science Indicators (NSI), da Thomson Reuters, obtidos a partir da indexação de tudo que foi publicado, no período, em revistas e periódicos científicos, o que classificamos como disseminação científica (SILVA, 2017, p. 39).

Esses dados devem reforçar para a sociedade que a o país segue trilhando um caminho pela valorização da pesquisa, da ciência e da tecnologia. Mas como bem nos aciona Lima (2017) a divulgação da ciência, assim como o gosto pela pesquisa e de explorar os resultados de projetos científicos sempre foi um grande desafio no Brasil, principalmente, no nosso âmbito de estudo, a comunicação. O que chega a ser um detalhe preocupante tendo em vista que "a ciência está no dia a dia da população. Está 


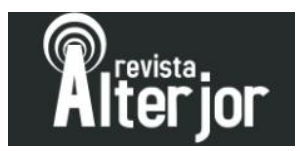

no interruptor de energia elétrica, nos alimentos que levamos para as nossas casas e nas multifunções de um aparelho celular, por exemplo" (MOREIRA, 2017, p. 14).

Para Santaella (2001) essa realidade chega a ser mais complexa, pois para a pesquisadora a ciência diz respeito ao fruto de "uma busca concreta de um grupo real de pessoas vivas, caracterizando-se desse modo, como algo em permanente metabolismo e crescimento" (SANTAELLA, 2001, p.102). Chaimovich (2000) relata que a relação do estado com o desenvolvimento tecnológico deve ser evidente, assim como nos países desenvolvidos, pois como infere o autor "[...] assumir esta relação no Brasil poder-se-ia tornar um fator determinante no futuro do sistema de ciência-tecnologia e inovação e, por decorrência, no desenvolvimento" (CHAMOVICH, 2000, p. 135). Sabemos da importância do poder de intervenção do estado nos investimentos relativos à produção de ciência no Brasil e mais ainda, estamos cientes de como o governo federal direciona seu olhar para a pesquisa através da comunicação realizada em sites institucionais dos seus órgãos de amparo a pesquisa, além de toda divulgação realizada nos últimos anos nos meios de comunicação.

Entretanto, reiteramos que, além do governo, as organizações, enquanto agentes sociais complexos, envoltas a subjetividades, devem acreditar e investir na produção da ciência brasileira. Ressaltamos que esta vertente de atuação e investimentos no âmbito científico, social e educativo se caracteriza como um campo de atuação que pode beneficiar as estratégias de relacionamento junto aos seus públicos de interesse, como também promover investimentos em ciência através de um composto de ações articuladas junto a pesquisadores nos programas de pós-graduação no país e ao próprio governo federal.

Para demonstrar essa possibilidade de atuação, trazemos um case empírico, realizado na pesquisa de mestrado da presente autora junto ao Programa de Pós Graduação em Comunicação na Pontifícia Universidade Católica do Rio Grande do Sul, a PUCRS. O estudo intitulado Memória Institucional e sua possibilidade educativa: análise da revista "O Sucesso" do Grupo Claudino trouxe um estudo exploratório (GIL, 2002) e documental (MOREIRA, 2005), que obteve resultados que direcionaram a pesquisa para o doutorado no Programa de Pós Graduação em Comunicação na 


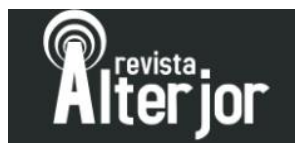

ECA/USP no âmbito da Gestão Educativa nos ambientes empresariais no Brasil, área pouco explorada no âmbito científico, mas que acreditamos que pode trazer processos inovadores ligados ao âmbito educativo e científico, dado o envolvimento do conglomerado empresarial com projetos nestas áreas desde a década de 1950.

\section{AS ORGANIZAÇÕES - AGENTES SOCIAIS EM CONSTANTE MODO DE ATUAÇÃO}

As organizações são núcleos de empregabilidade e convivência social que se caracterizam como agentes que interagem diretamente com as sociedades. De acordo com Nassar (2012) e Kunsh (2003) desde a década de 1980, especialmente nos estudos de Comunicação Organizacional do Brasil, podemos observar como as organizações ampliaram o seu campo de atuação frente aos seus públicos de interesse. Pensamos que essa realidade deve-se ao fato do próprio acompanhamento das evoluções ligadas a globalização, ao avanço do capitalismo e ao surgimento dos projetos no âmbito da responsabilidade e empreendedorismo social. Outro fator decisivo, seria o próprio estreitamento dos laços efetivos junto aos públicos ligados à organização, sejam eles os internos (funcionários/parceiros) ou externos (consumidores).

Para Kunsch (2016) as organizações possuem um poder na sociedade envolto a novos desafios, pois elas são parte integrante de um sistema econômico global. O que visualizamos agora, é que os gestores devem acompanhar de perto as novas tendências sociais no âmbito da gestão e que acima de tudo devem desenvolver uma cultura de excelência, sempre pensando na qualidade e responsabilidade institucional da corporação. Inferimos que através dessas ações a empresa firma uma imagem de envolvimento social diante de seus públicos. Para Hall (2016):

À medida que adentramos um novo século, as empresas se destacam como as instituições mais poderosas do planeta. Há 700 anos era a religião. As catedrais, as mesquitas e os templos são testemunhas da primazia da religião organizada naquela época. Há duzentos anos era o estado. Nenhum passeio estaria completo sem uma visita aos palácios impressionantes, às assembleias legislativas e aos complexos governamentais, os quais nos lembram de como o

Revista ALTERJOR

Grupo de Estudos Alterjor:Jornalismo Popular e Alternativo (ECA-USP)

Ano 10 Volume 02 Edição $22 \quad$ Juho- Dezembro de 2020

Avenida Professor Lúcio Martins Rodrig̉ues, 443, Cidade Universitária, São Paulo, CEP: 05508-020 
governo era centralmente importante na era do iluminismo. Hoje, as instituições mais poderosas são as empresas: veja as torres dos escritórios, bancos e centros comerciais que dominam as grandes cidades. Embora ninguém negue a importância permanente e crucial dos governos, da religião e da sociedade civil, não há dúvida de que o comércio se tornou uma instituição dominante (HALL, 2016, p. 222-223).

A citação deixa visível o poder e o destaque que as empresas obtiveram ao longo dos anos. Na contemporaneidade, Mardsen e Towley (2001) ressaltam que as organizações se caracterizam como abstrações dos indivíduos e das relações sociais entre eles que acaba incidindo em uma forma moderna de vida social. Segundo Chanlat (1993) as organizações contemporâneas "exercem influência cada vez maior sobre as condutas individuais, sobre a natureza, as estruturas socioeconômicas e a cultura, os que a leva a se transformar em elementos-chave das sociedades" (CHANLAT, 1993, p. 40). $\mathrm{O}$ autor ainda infere que dessa forma as empresas contribuem para edificar uma ordem social mundial. É, portanto, diante desta realidade que acreditamos que as mesmas devem investir nas possibilidades de atuação educativa e científica.

Mas como então direcionar as influências e investimentos realizados nos ambientes organizacionais para o âmbito científico, educativo e social? Para Kaplún (1999), a construção do conhecimento é resultado de uma interação: alcança-se a organização e a clareza desse conhecimento ao convertê-lo em um produto comunicável e efetivamente comunicado. Portanto, "a reconfiguração nos modos de produzir, operar e pôr em circulação o conhecimento e a informação é uma realidade [...]" (CITELLI, 2009, p. 159). Para Fígaro (2009) "trata- se de compreender a gestão como um processo de conhecimento [...]" (FÍGARO, 2009, p. 137).

“A adaptação que se impõe às organizações, impulsionada pelas inovações ao nível da concorrência, pelas novas tecnologias e as pelas mudanças sociais e econômicas incentivam à criação de conhecimento" (SEQUEIRA, 2008, p. 8). Para a autora, uma vez que a organização investe na criação, desenvolvimento e transferência de saber, faz todo o sentido que ela desenvolva esforços no sentido de promover uma cultura que facilite a sua utilização constantemente. Pensamos que é exatamente esta 


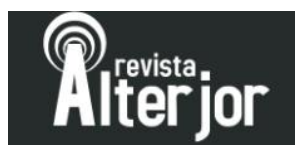

cultura que contribuirá com a ampliação dos investimentos na ciência e no desenvolvimento da sociedade brasileira.

Deste modo é de extrema importância por parte das organizações avaliar e investir nas possibilidades de atuação no campo científico e educativo junto aos seus públicos de interesse e a própria sociedade. Assim podem ser construídas novas instâncias de gestão, difusão de saber e conhecimento, que proporcionam uma variável de possibilidades de atuação das empresas tanto em âmbito regional como global, pois "hoje o conhecimento científico é de domínio de um pequeno número de pessoas, apesar de todos os esforços já empreendidos em publicações impressas, em programas de televisão e sites de popularização da ciência" (MOREIRA, 2017, p.19).

De acordo com Baccega (2009) o papel regulador que as empresas exercem tem importância fundamental na luta pela atribuição de significados sociais. Para Sequeira (2008), as atuais condições econômicas, sociais e culturais acabam por esgotar o tecnicismo, influenciando assim, uma sociedade da informação, onde o saber e o conhecimento se tornam essenciais para o desenvolvimento organizacional. Mas a autora também nos chama a atenção para o fato de que muitas organizações praticarem estas ações até certo ponto e que poucas conseguem sucesso, pois confiam em situações esporádicas ou exemplos isolados. "As organizações, para serem eficientes na gestão de aprendizagem tem de criar sistemas e processos onde ressaltem essas atividades e integrá-los na trama das operações quotidianas" (SEQUEIRA, 2008, p. 13). No próximo subitem iremos apresentar o case do Grupo Claudino, que ao longo das décadas de atuação no Brasil investe na realização de ações, produtos e projetos no âmbito de uma gestão voltada para a promoção de educação e ciência principalmente no Nordeste do país.

\section{GRUPO CLAUDINO - CRIAÇÃO E CAMPOS DE ATUAÇÃO NO BRASIL}

O Grupo Claudino é um conglomerado empresarial que contempla algumas empresas que atuam desde a década de 1950, em diversos setores econômicos, no 


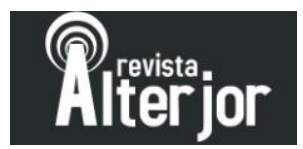

Brasil. De acordo com as informações divulgadas em seu site institucional ${ }^{3}$ e nas mídias impressas produzidas pelo conglomerado, o grupo já foi responsável pela estruturação, no mercado, de 13 empresas nos mais diversos segmentos. São elas: Paraíba, Socimol, Guadalajara, Sucesso Publicidade, Sucesso Construtora, Halley Cartonagem, Halley Gráfica e Editora, Frigotil, Ônix Indústrias de Colchões de Espuma, Colon, Teresina Shopping, Houston e Audax. Algumas já atuam no mercado internacional, exportando seus produtos. Com atuação mais presente nas regiões Norte e Nordeste, a sede do conglomerado está instalada em Teresina, capital do estado do Piauí.

De acordo com João Claudino Fernandes, presidente do grupo, em declaração na publicação institucional Grupo Claudino: Empresas e ações sociais, divulgada em maio no ano de 2012, o grupo movimentava, naquele ano, mais de 60 mil empregos diretos e indiretos, distribuídos em todo o país. Em entrevista ${ }^{4}$ publicada na revista Cidade Verde, com o presidente do grupo, João Claudino, Cury (2016) destacou que no ano de 2015, o faturamento das empresas do conglomerado chegou a $\mathrm{R} \$ 3$ bilhões, segundo informações repassadas pela Sociedade Brasileira de Varejo e Consumo (SBVC). Para Viana (2015):

O Grupo Claudino tornou-se, nas últimas décadas, a maior rede de empresas do estado do Piauí, sendo responsável pela criação de inúmeros empregos diretos e indiretos, além de ser o segundo maior arrecadador em território piauiense, atuando em diversas esferas do mercado (VIANA, 2015, p. 123).

Durante seus mais de 50 anos de atuação, o grupo conviveu com momentos importantes na economia e no desenvolvimento do Brasil, principalmente do Nordeste. O presidente do grupo, João Claudino, em declaração na publicação institucional Grupo Claudino: Empresas e ações sociais ${ }^{5}$, publicada em maio de 2012, destaca que,

\footnotetext{
${ }^{3}$ Disponível em: www.grupoclaudino.com.br. Acesso em 30 de julho de 2019. Para maiores informações consultar a dissertação da autora, intitulada "Memória Institucional e sua possibilidade pedagógica: análise da revista O Sucesso", publicada na PUCRS.

${ }^{4}$ Entrevista intitulada $O$ Segredo do Sucesso, realizada por Jordana Cury, com João Claudino Fernandes, presidente do Grupo Claudino, em 20 de março de 2016. Publicada na Revista Cidade Verde, v. 6, n. 133, p. $49-53$.

${ }^{5}$ GRUPO CLAUDINO, PERFIL DO GRUPO CLAUDINO: EMPRESAS E AÇÕES SOCIAIS. Teresina: Halley S/A Gráfica e Editora, 2018
}

Revista AL TERJOR

Grupo de Estudos Alterjor:Jornalismo Popular e Alternativo (ECA-USP)

Ano 10 Volume 02 Edição $22 \quad$ Juho- Dezembro de 2020

Avenida Professor Lúcio Martins Rodriģues, 443, Cidade Universitária, São Paulo, CEP: 05508-020 


\section{Ritiejor}

no momento da implantação do Armazém Paraíba, sua primeira empresa, ele já reconhecia a importância das questões relativas à globalização, novos mercados e regionalização. Para ele e seu irmão Valdecy Claudino, essa percepção orientou as estratégias de expansão do grupo, assim como os conceitos de comunicação e marketing, buscando implantar a marca em nível local, regional e nacional. Ao longo de sua estruturação, e à medida que o conglomerado sentiu necessidade, o Grupo Claudino empreendeu outras estratégias para reforçar a fidelização do relacionamento, junto aos seus públicos de interesse e uma delas foi o envolvimento com projetos educativos e estudos científicos.

\section{IVESTIMENTOS NA EDUCAÇÃO E CIÊNCIA NO NORDESTE}

Os investimentos em projetos no âmbito educativo são realizados, pelo grupo, desde a década de 1960. Em 1969, na cidade de Luís Gomes, no estado do Rio Grande do Norte, cidade natal da família Claudino, o grupo criou a Escola Profissional Francisca Fernandes Claudino, que, atualmente, funciona como Fundação. Ela tinha como objetivo disponibilizar educação de nível profissionalizante e contribuir para o desenvolvimento da cidade. Com a expansão do Armazém Paraíba, primeira empresa do grupo, os projetos educacionais foram realizados e difundidos nas outras comunidades onde o conglomerado atuou - principalmente, na região Nordeste.

Com a criação da revista institucional O Sucesso, em 1972, muitos assuntos ensinados no âmbito escolar - conteúdos ligados às áreas de ensino de História, Língua Portuguesa, Geografia e Biologia, pesquisas científicas, por exemplo - eram divulgados nas edições do periódico. A revista possuía uma página destinada a esses conteúdos, assim como sessões destinadas a poemas, literatura, leituras sobre conhecimentos gerais, abordando histórias de personalidades que foram referência, no âmbito da educação e cultura no país. Questões sobre atualidades, economia e História do Brasil, muitas vezes, também foram explanadas nas páginas do periódico.

Em 1973, o Armazém Paraíba lançou a sua própria Casa do Estudante, em Teresina (PI). Seu surgimento teve como objetivo disponibilizar, aos funcionários que 


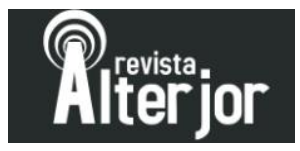

vinham das cidades do interior e não tinham moradia fixa na capital, um lugar para morarem e estudarem com incentivos da organização. O grupo desenvolveu projetos e ações de valorização à educação, ao longo de sua atuação. Para o público interno, os investimentos são destinados à alfabetização de adultos, de forma que eles tenham acesso ao ensino médio, cursinhos pré-vestibulares, ensino universitário, aulas de idiomas, cursos de informática e cursos técnicos. As aulas são realizadas em duas frentes: nas empresas ou em escolas e faculdades que mantêm convênio com o grupo.

Em 1974, é inaugurada a Escola Profissional Lica Claudino, na cidade de Uiraúna, no estado da Paraíba, que, atualmente, funciona como Fundação. A escola tinha como objetivo proporcionar aos moradores da região uma formação profissional nas áreas de datilografia, informática, música, cultura, teatro, aulas de dança, dentre outros temas. É importante destacarmos que as duas Fundações mantidas pelo grupo também produzem suas próprias mídias, duas revistas que proporcionam, a jovens universitários e do meio acadêmico, escreverem sobre os mais diversos temas, explanando as suas opiniões nas páginas dos periódicos. São elas: a revista FELC (Fundação Educacional Lica Claudino) e a revista FUNFFEC (Fundação Francisca Fernandes Claudino).

É importante sinalizar que a FUNFFEC ao longo dos anos vem conseguindo conquistar a valorização no âmbito científico internacional. Além de premiação recebida pelos seus alunos no Canadá, professores de instituições internacionais deste país já entraram em contato com a gestão para poder oferecer intercâmbio educacional e cientifico para os alunos sediados no nordeste e beneficiados pelo Grupo Claudino.

De acordo com a equipe de comunicação do conglomerado empresarial, todas essas ações, relativas ao âmbito educacional e científico internamente, são desenvolvidas tendo como objetivo o crescimento profissional e pessoal dos funcionários do conglomerado. Já no âmbito externo elas visam dar oportunidades de conhecimento para as comunidades que o grupo interage. O programa de educação estimulou o retorno de muitos funcionários aos estudos. $\mathrm{O}$ grupo mantém convênio com instituições de ensino superior, oferecendo bolsas de estudos para seus funcionários e para seus filhos de até 13 anos de idade. São oferecidos uniformes e material escolar, 


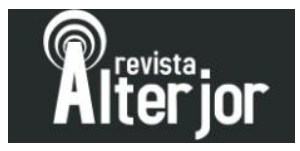

além de bolsas de estudos em escolas e faculdades particulares, nas localidades onde o grupo atua. O conglomerado também dispõe de biblioteca e videoteca com revistas, vídeos e livros, ligados a diversas áreas de ensino, disponíveis para empréstimo aos funcionários do grupo.

Em 2005, foi inaugurado o Centro Educacional João Claudino, na cidade de São João do Piauí. O centro realiza atividades nas áreas de educação, esportes e fóruns de conhecimento com várias temáticas de estudo. Em suas campanhas de doações, as empresas do grupo arrecadam materiais escolares para as comunidades carentes. Para o presidente João Claudino, os investimentos em educação sempre tiveram prioridade na gestão. Para o empresário:

Pra mim é uma coisa que é sempre bom falar, escrever, como ouvir sobre educação, é um aprendizado. A educação está acima de tudo e devemos repassar. O meu interesse pela educação em si devo a minha mãe. Tudo para minha mãe era a educação, o pensamento dela era a educação, mesmo com poucas condições financeiras ela nos incentivava muito, eu e meus dezesseis irmãos a estar nesse caminho. Admiro muito as pessoas que querem crescer na vida através do estudo (CLAUDINO, 2017) ${ }^{6}$.

O grupo ainda investe em projetos e publicações de ordem impressas, ligadas à educação, ciência e à cultura, patrocinando ou produzindo material para futura divulgação, junto à comunidade. Diante das ações explanadas, as empresas do grupo já foram reconhecidas com prêmios emitidos pela UNICEF, pela Fundação Abrinq e prêmio SESI de Qualidade. Muitas das organizações ainda possuem os prêmios Newton Rique, o prêmio Desempenho Brasil, além do Troféu Caneleiro na categoria responsabilidade social, oferecido pelo Jornal O Dia, em Teresina, e Troféu Maiores e Melhores.

No âmbito científico, com base na catalogação das 400 edições da revista "O Sucesso" para a pesquisa do mestrado verificamos que o grupo ainda na década de 1970 foi tido como objeto de estudo em congressos nacionais de comunicação nos estados da Bahia e no Maranhão por seu modelo de gestão. O presidente do grupo João Claudino

\footnotetext{
${ }^{6}$ Depoimento extraído da entrevista cedida para a dissertação do mestrado, em 27 de outubro de 2017. 


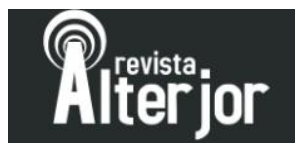

Fernandes sempre foi figura presente em congressos e universidades do Nordeste, seja como homenageado ou ministrando palestras sobre sua atuação educativa no mercado. Mais de 40 títulos de cidadania foram emitidos para o gestor por seu envolvimento com as causas educativas e sociais nos municípios em que o grupo está presente.

O grupo sempre divulgou em sua revista institucional uma página destinada para as descobertas científicas, recebeu inúmeras turmas de universitários em suas empresas, assim como promoveu aulas práticas nas em suas respectivas sedes. Instituições como a Universidade Federal do Piauí (UFPI), o Instituto Federal do Piauí (IFPI), e a Faculdade Estácio Ceut em Teresina ao longo dos anos realizaram homenagens e palestras com foco nas ações do grupo e nas estratégias de gestão social e educativa por parte da presidência da organização. Na década de 2000, por exemplo, o Armazém Paraíba foi tema de debate no II Congresso de Comunicação e Marketing do Ceut. Outras empresas do grupo participaram das jornadas cientificas organizadas pelo IFPI. Alguns funcionários também tiveram oportunidades de fazer cursos fora do estado em centros universitários renomados, como a ESPM, localizada em São Paulo.

Como objeto empírico de análise e pesquisa o grupo já foi estudado por alguns pesquisadores em nível de Monografia, Dissertação e Tese. Vale ressaltar que o grupo autoriza as pesquisas, se envolve no planejamento documental, possibilita o desenvolvimento de entrevistas, apoiando assim, a produção cientifica e acadêmica no Brasil. Como exemplo destas investigações científicas podemos citar os seguintes estudos: 1) Uso da informação contábil-financeira para a tomada de decisão: o caso de uma empresa comercial, Dissertação de autoria de Valtemar de Andrade realizada na UFPI e em parceira com a UFMG; 2) Análise das ações de FolkMarketing do Armazém Paraíba na $250^{\circ}$ Romaria de Nossa Senhora da Penha, TCC de conclusão de curso, de autoria de Kamila Gonçalves e Ruth Rocha, realizado na UFPI; 3) Comprometimento Organizacional: Um Estudo de Caso na Empresa Armazém Paraíba de Picos-PI, TCC de conclusão de curso, de autoria de Fabio de Moura, Flaviane Maria e Ivana Teresa, realizado na UFPI 4) Memória Institucional e sua possibilidade educativa: Análise da revista “ O Sucesso" do Grupo Claudino, dissertação realizada na PUCRS. 5) Gestão 


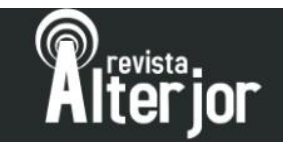

Educativa nos ambientes empresariais brasileiros, de autoria de Keynayanna Fortaleza, projeto de doutorado em andamento na USP.

Além destes estudos científicos, o grupo também é objeto de estudo exposto como base de análise em congressos nacionais e internacionais, como por exemplo, no Intercom, Ibercom, ALAIC, tendo suas estratégias de comunicação, sistema contábil e gestão educativa como fonte de análises. No âmbito da organização de eventos ligados a ciência, o grupo junto com o Ministério da Cultura, por meio da Fundação Lica Claudino é um dos patrocinadores do Festival Internacional das Culturas Populares do Alto Sertão Paraibano - evento inserido dentro da Rota do Sol que ampara nove municípios do sertão da Paraíba com educação, arte e cultura.

\section{CONSIDERAÇÕES FINAIS}

A valorização da ciência e sua disseminação ainda é um grande desafio para a sociedade brasileira. Como bem relatamos na introdução deste artigo, este é um problema social de ordem cultural. Nosso país sempre teve muitas falhas com a gestão educativa, base para as articulações que envolvem a ciência. Nosso governo ao longo dos anos lida com projetos falhos e uma legislação que anda a passos lentos na valorização da pesquisa científica no país. Bem sabemos ao transitar no universo das instituições públicas com as carências e limitações de bolsas científicas que prejudicam o desenvolvimento de muitas pesquisas.

Mas, mesmo diante destas dificuldades, o Brasil ainda lidera o número de publicações e projetos na América Latina. O pesquisador luta, persevera, contribui com o seu pensamento crítico, beneficiando assim, a educação e a ciência brasileira. Pensamos que essa realidade pode melhorar, ser ampliada com a ajuda de investimentos por parte da iniciativa privada. Algumas organizações já realizam investimentos, mantém suas incubadoras e disponibilizam bolsas de estudos para alunos em alguns programas de pós-graduação no país. Nesse artigo, trouxemos o case de um conglomerado empresarial do Nordeste que desde a década de 1950 é bastante envolvido com as questões educativas e em disseminar a produção científica em nosso 


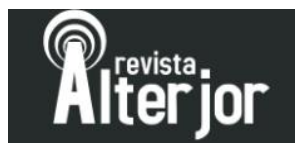

país. O grupo se envolveu em ações, produtos e projetos, seja criando, patrocinando ou participando de eventos científicos e acadêmicos. Atualmente o presidente do grupo João Claudino Fernandes, emitiu declaração institucional autorizando o desenvolvimento de pesquisa de doutorado na ECAUSP, além de ceder material documental e entrevistas para o estudo. O próprio gestor acompanha o desenvolvimento das pesquisas que envolvem o grupo e publica as mesmas em suas mídias institucionais.

Este é um caso positivo que pode servir de estímulo para outros gestores brasileiros que desejam investir e valorizar a pesquisa e ciência no nosso Brasil. Tal investimento irá incidir na promoção de uma gestão educativa que além de valorizar a ciência, também promoverá a educação e a cidadania para milhares de brasileiros que desejam ter novas oportunidades de ensino e assim possam compreender melhor a importância da ciência em sua vida e suas realidades, tendo em vista os agentes sociais que são.

\section{REFERÊNCIAS BIBLIOGRÁFICAS}

BACCEGA, Maria Aparecida. Campo Comunicação/Educação: mediador do processo de recepção. In: Maria Aparecida Baccega e Maria Cristina Castilho Costa (Orgs). Gestão da Comunicação. Epistemologia e pesquisa teórica. São Paulo: Paulinas. 2009. p. 13-26.

BURKETT, Warren. Jornalismo Científico. Rio de Janeiro: Forense Universitária. 1990.

CITELLI, Adílson. Comunicação/ Educação: situações. In: Maria Aparecida Baccega e Maria Cristina Castilho Costa (Orgs). Gestão da Comunicação. Epistemologia e pesquisa teórica. São Paulo: Paulinas. 2009. p. 145-160.

CURY, Carlos Roberto Jamil. Financiamento da Educação Brasileira: do subsídio literário ao FUNDEB. In: Educação \& Realidade, Porto Alegre, v. 43, n. 4, p. 1217- 1252, out./dez. 2018.

CHANLAT, Jean Francois. Por uma antropologia Humana nas organizações. In: $O$ individuo na organização. Jean François Chanlat (coordenador). São Paulo: Atlas, 1993.

CHAIMOVICH, Hernam. Brasil, Ciência e Tecnologia. Revista Estudos Avançados 14 (40), 2000. Disponível em: 


\section{Rireijor}

http://www.scielo.br/scielo.php?script=sci_arttext\&pid=S0103- 40142000000300014 . Acesso em: 20 de junho de 2019.

FÍGARO, Roseli. Políticas de Comunicação no mundo do trabalho. In: Maria Aparecida Baccega e Maria Cristina Castilho Costa (Orgs). Gestão da Comunicação. Epistemologia e pesquisa teórica. São Paulo: Paulinas. 2009. p. 125- 144.

GIL, A. C. Como Elaborar Projetos de Pesquisa. São Paulo: Atlas, 2002.

HALL, Stuart L. Capitalismo na encruzilhada. São Paulo. Editora: Bookman, 2016

KAPLÚN, Mário. Processos Educativos e canais de comunicação. Acesso em: 24/01/2017. São Paulo, (14): 68 a 75, jan/abr.1999. Disponível em: Disponível em: http://www.revistas.usp.br/comueduc/article/view/36846. Acesso em: 24/01/2017.

KUNSCH, Margarida K. (Org). Comunicação Organizacional estratégica:aportes conceituais e aplicados. São Paulo: Summus. 2016.

Paulo: Summus. 2003.

Planejamento de Relações Públicas na Comunicação Integrada. São

LIMA, Maria Santíssima. Refletir, compreender, traduzir, teclar, despertar: o desafio nosso de falar de ciência. In: Benedito Dielcio Moreira e André Chaves de Melo (Orgs). Divulgação Científica: debates, pesquisas e experiências. Cuiabá: EdUFMT, 2017. p. 10-13. 